\title{
Meridional Heat Transport by the Subtropical Cell
}

\author{
BARRY A. KLINGER \\ Nova Southeastern University Oceanographic Center, Dania Beach, Florida \\ JOCHEM MAROTZKE* \\ Center for Global Change Science, Massachusetts Institute of Technology, Cambridge, Massachusetts
}

(Manuscript received 15 July 1998, in final form 10 May 1999)

\begin{abstract}
The wind-driven circulation adds a significant contribution to poleward meridional heat transport. Numerical models indicate that equatorward of $\phi_{0}$, the zero wind stress latitude $\left(30^{\circ}\right.$ lat $)$, most of the wind-induced heat transport is due to the meridional overturning circulation known as the subtropical cell. The volume transport of this overturning is approximately given by the surface Ekman transport. By combining this fact with the assumption that Ekman-downwelled water approximately follows isotherms except near the equator, the authors derive an expression for the meridional heat transport that depends only on wind stress and surface temperature. The expression is confirmed in numerical models with simplified geometry and forcing. Numerical results indicate that peak heat transport due to the subtropical cell is about $0.1 \times 10^{15} \mathrm{~W}$ for the North Atlantic and $0.3 \times 10^{15}$ W for the North Pacific.
\end{abstract}

\section{Introduction}

Both the thermohaline and wind-driven ocean circulation are responsible for considerable meridional heat transport. For basin-scale thermohaline circulation in the absence of wind forcing, the relationship between volume transport and meridional heat transport is a fairly simple one. The "overturning cell" strength in the latitude-depth plane is of the same order as the Stommel-Arons "gyre" circulation in the horizontal plane. At the same time, the temperature difference between the surface limb and the deep limb of the overturning cell is much greater than zonal temperature differences at any latitude. Together, these two facts imply that meridional heat transport due to the thermohaline circulation is dominated by the "overturning component," which scales as $\Phi \overline{\Delta \theta}$, where $\Phi$ is the volume transport of the overturning cell and $\overline{\Delta \theta}$ is the zonally averaged temperature difference between the surface and the bottom.

In contrast, the heat transport due to wind-driven flow

\footnotetext{
* Current affiliation: School of Ocean and Earth Science, University of Southampton, Southampton, United Kingdom.
}

Corresponding author address: Dr. Barry A. Klinger, Oceanographic Center, Nova Southeastern University, 8000 North Ocean Drive, Dania Beach, FL 33004-3078.

E-mail: Klinger@ocean.nova.edu cannot be so cleanly related to an overturning mode. For one thing, wind-driven overturning cells, which consist of Ekman transports that are mass-compensated by deeper return flow, have considerably smaller volume transport than the associated horizontal gyres. For another, the wind-driven circulation is relatively weak below the thermocline, so the relevant vertical temperature contrast for meridional overturning is not necessarily as large as $\Delta \theta$ mentioned above. In fact, it can be argued that both kinds of motion-horizontal gyres and vertical overturning cells - can be important for the heat transport. Bye and Veronis (1980), Wang et al. (1995), and Klinger (1996) derived scalings for the heat transport due to horizontal motion at midlatitudes. Here, we argue that the wind-driven meridional overturning makes an important contribution to heat transport in the Tropics and subtropics and demonstrate a simple law for the strength of such transport.

In general, both the ocean and the atmosphere are important conduits for meridional heat transport. It is in the Tropics that the ocean's contribution becomes especially important (e.g., Peixoto and Oort 1992, p. 347). The western boundary currents in this latitude range do not have as strong a temperature contrast with neighboring same-latitude water as the western boundary currents at $30^{\circ}-40^{\circ}$. Thus, we would not expect an important gyre contribution in the Tropics. However, there is a very clear meridional overturning reaching from the equator to the subtropics. This overturning, known as the subtropical cell (McCreary and Lu 1994; 
(a) Meridional Overturning and Temperature

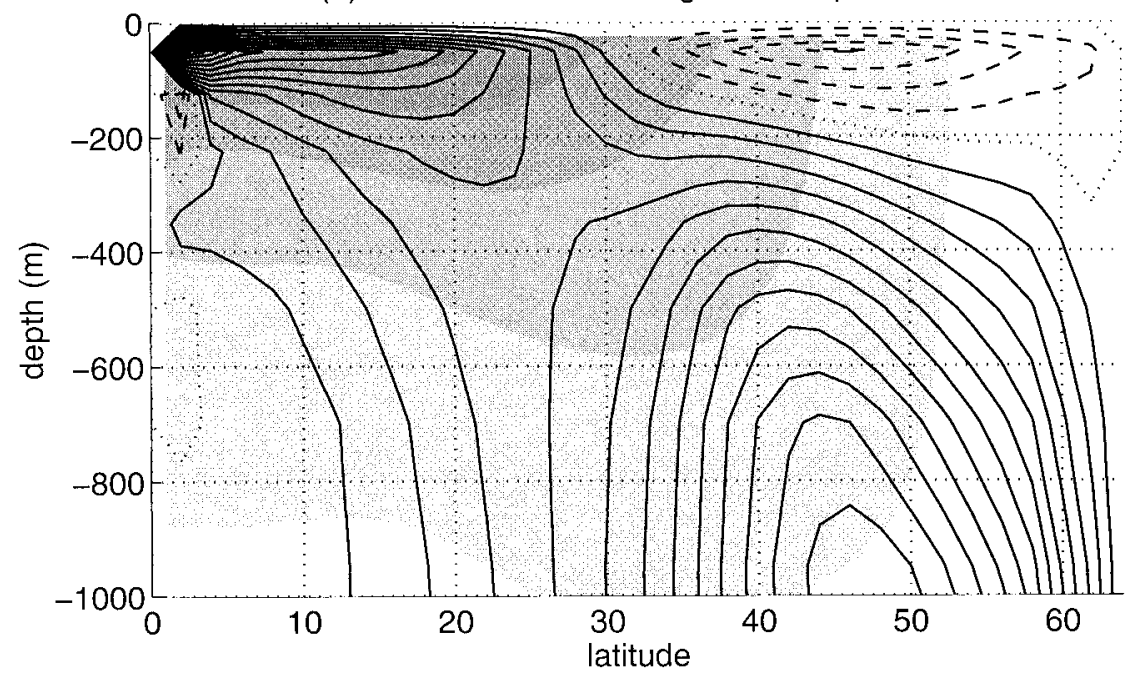

(b) Meridional Overturning: Difference of Wind and No Wind

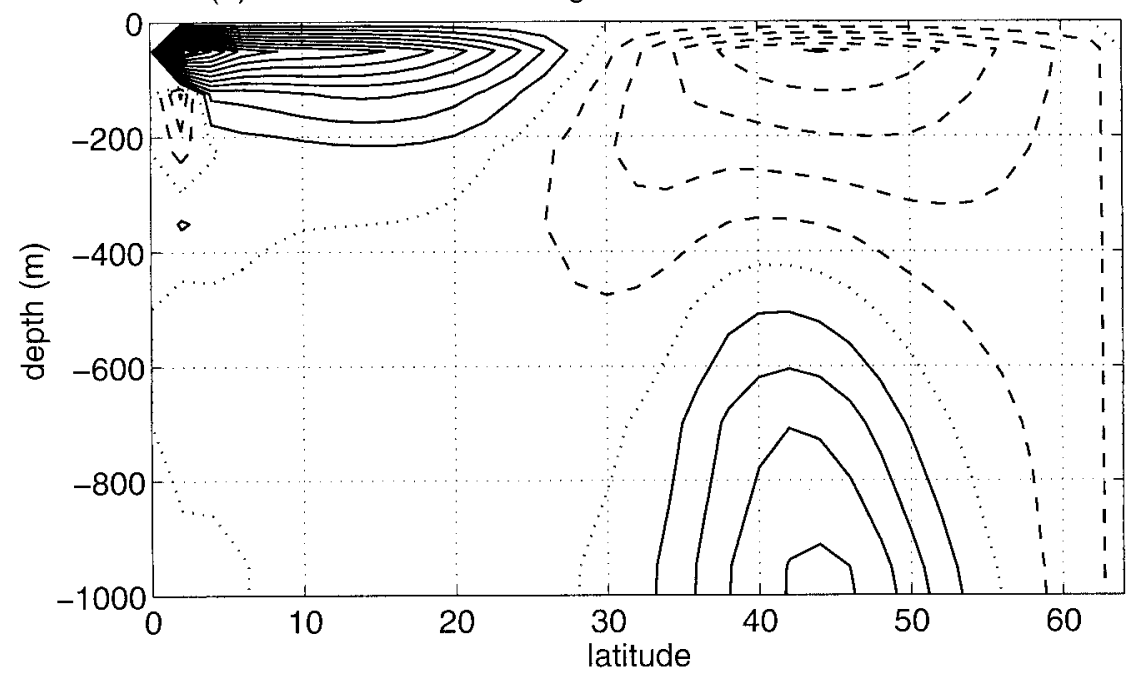

FIG. 1. (a) Meridional overturning streamfunction (lines) and zonally averaged temperature (shading) for high-resolution numerical experiment of a wind- and buoyancy-driven circulation in a single hemisphere basin with strong restoring of surface temperature (see section 3). Meridional overturning contour interval is $1 \mathrm{~Sv}$; dashed curves represent negative values; flow is clockwise around a high and anticlockwise around a low. Temperature contour interval is $4^{\circ} \mathrm{C}$, with white representing the $0^{\circ}-4^{\circ} \mathrm{C}$ interval. (b) Meridional streamfunction, difference between experiments with and without wind forcing (contour interval is $1 \mathrm{~Sv}$ ).

see also Bryan 1987), consists of poleward surface Ekman transport that sinks via subduction in the region nearest the equator of the subtropical gyre and flows equatorward to the equator, where it upwells to complete the circuit. Figure 1a shows an example of this overturning from a numerical model, which will be described below.

As McCreary and Lu (1994) demonstrated, the strength of this overturning cell is approximated by the zonally integrated surface Ekman transport. Therefore, one important factor in the heat transport can be given simply from the surface boundary condition. To calculate the heat transport, the temperature contrast between the surface and deep limbs of the overturning must also be given. Some empirical studies have assumed that the deep return flow temperature is simply the depth-average temperature over the entire water column (e.g., Fu 1981; Hall and Bryden 1982; Kraus and Levitus 1986; Levitus 1987; Adamec et al. 1993). This has been demonstrated to be correct for the seasonally varying component of heat transport (Böning and Herrmann 1994; Lee and Marotzke 1998) but, as Fig. 
1 shows, this is rather implausible for the annual mean. For the seasonal signal, the barotropic response is stronger than the baroclinic response because at midlatitudes only barotropic Rossby waves can respond fast enough to an annual period. For time-mean flow, the wind-driven circulation is known to be concentrated in the thermocline, so some temperature typical of the thermocline seems more reasonable. This is consistent with the theory of forced geostrophic motion (e.g., Philander 1978; Willebrand et al. 1980), which suggests that for forcing on large spatial scales and periods of 300 days and longer, the response is trapped near the surface over a vertical scale less than the depth of the ocean. Bryden et al. (1991) use a depth-average over the top $700 \mathrm{~m}$, but even this choice is somewhat arbitrary.

If we take the view that the Ekman component has physical meaning as the heat transport by the shallow, wind-driven overturning, how can we determine this temperature? Even if we assume that the wind-driven return flow is largely confined to the thermocline, a wide range of heat transports are possible, ranging from a very small value if most of the flow is just below the Ekman layer to a rather large value if the deep flow is near the bottom of the thermocline.

The pathways of the wind-driven water are more complicated than either Fig. 1 or traditional horizontally averaged views suggest (Lu et al. 1998). However, Luyten et al.'s (1983) picture of the thermocline offers a useful simplification. In this conception, flow beneath the surface mixed layer and away from the western boundary current is assumed to be largely adiabatic. Once water subducts, it flows along isotherms on its way toward the equator (Pedlosky 1987). Numerical simulations with vertical mixing at least as large as the real ocean support this picture (Cox and Bryan 1984). Cooling on the poleward limb occurs primarily in the surface mixed layer, while warming takes place in the strong mixing region in the eastern equatorial ocean, where thermocline water upwells (Lu et al. 1998). In our model, the mixed layer approximately coincides with the Ekman layer in the latitudes of the subtropical cell, the polar boundary of which is at $\phi_{0}=30^{\circ} \mathrm{N}$.

If the flow below the Ekman layer is along isotherms, then there is a clear way to correlate the meridional volume transport with the temperature as a function of depth. At any latitude and depth, we merely follow an isotherm to its ventilation latitude. The net volume transport of water pumped out of the Ekman layer at the ventilation latitude is the volume of water flowing equatorward at the corresponding depth. Nurser and Marshall (1991), Marshall et al. (1993), and Huang and Russell (1994) show that the subduction rate is not necessarily equal to the Ekman pumping. However, the major differences between Ekman pumping and the subduction rate occur in regions where the mixed layer depth is rapidly changing. This is not an issue in our numerical experiments, where the mixed layer depth is uniform equatorward of $30^{\circ} \mathrm{N}$; we discuss its relevance to the real ocean in the conclusion.

In the next section, we use the relationship among meridional volume transport, Ekman pumping, and temperature to derive an expression for the heat transport. We then compare this relation to numerical results in section 3 .

\section{Subtropical cell heat transport}

\section{a. Heat transport in temperature coordinates}

The heat transport at some latitude $\phi$ is given by

$$
H(\phi)=\int_{-D}^{0} \int_{W}^{E}\left(c_{p} \rho\right) v \theta R \cos (\phi) d \lambda d z
$$

where $c_{p}$ is the specific heat, $\rho$ is the density, $v$ is the meridional velocity, $\theta$ is the potential temperature, $R$ is the radius of the earth, $z$ is the depth, $\lambda$ is the longitude, $D$ is the ocean depth, and $W$ and $E$ are the longitudes of the western and eastern boundaries. We assume that

$$
\int_{-D}^{0} \int_{W}^{E} v R \cos (\phi) d \lambda d z=0 .
$$

In the following, we will not explicitly show the dependence of all variables on $\phi$. We also use the approximation that $c_{p}$ and $\rho$ are constants $\left(4000 \mathrm{~J} \mathrm{~kg}^{-1}\right.$ ${ }^{\circ} \mathrm{C}^{-1}$ and $1020 \mathrm{~kg} \mathrm{~m}^{-3}$ ), which follows from a consistent application of the Boussinesq approximation. The essential feature of meridional heat transport is that different temperature ranges have different northward or southward volume transports. Therefore, (1) can be simplified if we consider the dependence of velocity on temperature rather than on depth. In that case, we write (1) in $\theta-\lambda$ coordinates so that it becomes

$$
H=\left(c_{p} \rho R \cos \phi\right) \int_{\theta_{B}}^{\theta_{S}} \int_{w(\theta)}^{e(\theta)} v(\lambda, \theta) \theta z_{\theta}(\lambda, \theta) d \lambda d \theta,
$$

where $z_{\theta}=z_{\theta}(\lambda, \theta) \equiv \partial z / \partial \theta, \theta_{B}$ and $\theta_{S}$ are the minimum and maximum temperatures, and $w$ and $e$ are the western and eastern limits of a given isotherm. We assume that $\theta$ decreases monotonically with depth. We must take a few more mathematical steps before the expression simplifies. Integrating $v$ across the basin along an isotherm, we define a volume transport per temperature interval,

$$
V(\theta)=(R \cos \phi) \int_{w(\theta)}^{e(\theta)} v z_{\theta} d \lambda .
$$

We also need to define the auxilary quantity

$$
Z(\theta)=\int_{w(\theta)}^{e(\theta)} z_{\theta} d \lambda,
$$

which allows us to define $v^{\prime}$, the departure from the meridional velocity zonally averaged along an isotherm 
TABLE 1. Summary of numerical experiments.

\begin{tabular}{lll}
\hline \hline \multicolumn{1}{c}{ Parameter } & Symbol & \multicolumn{1}{c}{ Value } \\
\hline Vertical diffusivity momentum, tracers & $\left(\nu_{v,} \kappa_{v}\right)$ & $(1,0.5) \times 10^{-4} \mathrm{~m}^{2} \mathrm{~s}^{-1}$ \\
Horizontal tracer diffusivity & $\kappa_{H}$ & $10^{3} \mathrm{~m}^{2} \mathrm{~s}^{-1}$ \\
Horizontal momentum diffusivity (coarse res) & $\nu_{H}$ & $250 \times 10^{3} \mathrm{~m}^{2} \mathrm{~s}^{-1}$ \\
Horizontal momentum diffusivity (high res) & $\nu_{H}$ & $2.5 \times 10^{3} \mathrm{~m}^{2} \mathrm{~s}^{-1}$ \\
Isopycnal diffusivity (G-M run only) & $\kappa_{\mathrm{p}}$ & $2000 \mathrm{~m}^{2} \mathrm{~s}^{-1}$ \\
Momentum time step & $d t_{M}$ & $3600 \mathrm{~s}$ \\
Tracer time step (coarse res) & $d t_{T}$ & $5 \mathrm{~d}$ \\
Tracer time step (high res) & $d t_{T}$ & $2 \mathrm{~d}$ \\
\hline
\end{tabular}

$$
v(\lambda, \theta)=\frac{V(\theta)}{Z(\theta)}+v^{\prime}(\lambda, \theta) .
$$

It follows from (4), (5), and (6) that

$$
\int_{w(\theta)}^{e(\theta)} v^{\prime} z_{\theta} d \lambda=0,
$$

and this allows us to write (3) as

$$
H=\left(c_{p} \rho\right) \int_{\theta_{B}}^{\theta_{S}} V \theta d \theta .
$$

A streamfunction (in temperature coordinates), $\Phi$, can then be defined as

$$
V=-\frac{\partial \Phi}{\partial \theta} .
$$

Substituting (9) into (8), integrating by parts, using (2), and assuming that $\Phi=0$ at the upper and lower limits of the integral, we then have

$$
H=\left(c_{p} \rho\right) \int_{\theta_{B}}^{\theta_{S}} \Phi d \theta .
$$

\section{b. Subtropical cell}

Now we apply (10) to the region of the subtropical cell. If we assume that the dominant motion consists of flow sliding down isotherms equatorward and returning in the surface Ekman layer, then $V(\theta)$ is merely the Ekman pumping at the outcrop latitude of $\theta$. Integrating $V(\theta)$ in temperature to get $\Phi$ is equivalent to integrating the Ekman pumping in latitude, which merely gives the Ekman transport. Here we assume that neither wind nor sea surface temperature have significant zonal structure. The isotherm forming the bottom boundary of the subtropical cell outcrops at the latitude of zero wind stress, which is at temperature $\theta_{0}$. The heat transport can now be written

$$
H(\phi)=\left(c_{p} \rho R \cos \phi\right) \Delta \Lambda \int_{\theta_{0}}^{\theta_{S}(\phi)} \frac{\tau(\theta)}{\rho f} d \theta,
$$

where $\Delta \Lambda$ is the longitudinal width of the basin, $\theta_{S}(\phi)$ is the surface temperature, $\tau$ is the wind stress, and $f$ is the Coriolis parameter. The wind stress $\tau$ can be writ- ten as a function of $\theta$ if there is a one-to-one relationship between latitude and surface (zonal average) temperature. Note that (11) is a particularly convenient expression because it does not depend on any subsurface variables, such as isotherm depth as a function of latitude. If we know the surface wind field and the surface temperature, (11) yields the heat transport associated with the subtropical cell.

\section{Numerical experiments}

We test the expression (11) for heat transport with a primitive-equation numerical model using idealized geometry and forcing. The model is the Geophysical Fluid Dynamics Laboratory Modular Ocean Model (Pacanowski 1996), a primitive equation model in spherical coordinates in the horizontal and constant-depth coordinates in the vertical. We run the model with uniform vertical and horizontal diffusivity and viscosity (see Table 1) in statically stable regions; unstable regions undergo complete mixing in the vertical. Density is calculated via an approximation to the standard nonlinear equation of state. The basin is a sector that ranges from the equator to $64^{\circ} \mathrm{N}$, is $60^{\circ}$ wide, and is $4500 \mathrm{~m}$ deep. The model is forced by restoring surface temperature and salinity to zonally uniform values and by imposing a zonally uniform zonal wind stress at the surface. The model is also run without any wind so that wind effects can be compared to a windless base state. The model is run at coarse and high resolutions, with the temperature and salinity in the top $50 \mathrm{~m}$ of the ocean restored with a timescale of 30 days ("strong restoring") and 300 days ("weak restoring," coarse resolution only). Strong restoring is easier to analyze because the surface temperature is generally close to the reference temperature, though weak restoring may be a more realistic model of how the coupled ocean-atmosphere system reacts to large-scale ocean circulation features. These two cases probably bracket the actual equilibration time of the ocean surface to temperature forcing (see, e.g., Davis 1976; Rahmstorf and Willebrand 1995; Marotzke and Pierce 1997).

The default ("coarse") resolution is $4^{\circ}$ in latitude and $3.75^{\circ}$ in longitude, while high resolution is $2^{\circ}$ in latitude and in longitude varies from $0.5^{\circ}$ next to the western boundary to $3^{\circ}$ over approximately the eastern half of 
the basin. All the runs (except as noted below) have 15 levels varying in thickness from $50 \mathrm{~m}$ at the surface to $450 \mathrm{~m}$ in the deep ocean.

The restoring temperature is given by

$$
\theta_{*}=\Delta \theta[1+\cos (\pi \phi / 70)],
$$

where $\Delta \theta=13.5^{\circ} \mathrm{C}$ and $\phi$ is in degrees. The salinity curve $S_{*}(\phi)$ has the same shape-so that isotherms are everywhere parallel to isopycnals - but with range of $0.75 \mathrm{psu}$ and average value of $35.25 \mathrm{psu}$. The wind stress approximates the climatological zonal average wind and is given by

$$
\begin{gathered}
\tau(\phi)=(A / 2)\left[\frac{\sin \left(\Omega_{-} \phi-D_{-}\right)}{\Omega_{-}}+\frac{\sin \left(\Omega_{+} \phi-D_{+}\right)}{\Omega_{+}}\right. \\
\left.+\frac{\sin \left(D_{-}\right)}{\Omega_{-}}+\frac{\sin \left(D_{+}\right)}{\Omega_{+}}\right]-B,
\end{gathered}
$$

where $\Omega=\pi / 30, \gamma=2.2(\pi / 180), \Omega_{ \pm}=\Omega \pm \gamma, a=$ $35^{\circ}, b=40^{\circ}, A=0.65 \mathrm{~N} \mathrm{~m}^{-2}, B=0.025 \mathrm{~N} \mathrm{~m}^{-2}$, and $D_{ \pm}=a \Omega \pm b \gamma$. The wind stress curl, wind stress, and zonally integrated Ekman transport $\Phi_{\mathrm{E}}=R$ $\cos (\phi) \Delta \Lambda \tau /(f \rho)$ are shown in Fig. 2. The location of the subtropical and subpolar gyres, as well as a weaker tropical gyre, can be clearly seen in the wind stress curl profile, while the wind stress shows the trade winds and midlatitude westerlies. The Ekman transport profile shows that the poleward boundary of the subtropical cell is at $30^{\circ} \mathrm{N}$. The equatorward boundary of the subtropical gyre is at about $18^{\circ} \mathrm{N}$, but the Ekman transport shows that Ekman pumping (proportional to $d \Phi_{\mathrm{E}} / d \phi$ ) is actually negative everywhere equatorward of about $45^{\circ} \mathrm{N}$. Note that in the top layer of the numerical model, the meridional volume transport is not identical to $\Phi_{\mathrm{E}}$ because geostrophic and other terms also contribute to the flow. This is most apparent approaching the equator, where $\Phi_{\mathrm{E}}$ goes to infinity while the actual transport must go to zero. In our numerical experiment, the actual top level volume transport is roughly $70 \%$ of $\Phi_{\mathrm{E}}$ except equatorward of $10^{\circ} \mathrm{N}$, where the correspondence grows worse. Therefore, we will exclude this equatorial band when predicting the heat transport.

Meridional heat transport for no-wind runs has a roughly parabolic dependence on latitude (Fig. 3a), with a peak value of about $0.27 \mathrm{PW}\left(1 \mathrm{PW}=10^{15} \mathrm{~W}\right)$ that is rather small compared to estimates for the North Atlantic, where the heat transport of order $1 \mathrm{PW}$ is believed to be dominated by the overturning circulation (Hall and Bryden 1982; Roemmich and Wunsch 1985). This is at least partly a consequence of the small meridional extent of the basin, which excludes cross-equatorial and interbasin exchanges and therefore produces a smaller thermohaline overturning circulation than two-hemisphere basins (Klinger and Marotzke 1998) or multiplebasin oceans (Marotzke and Willebrand 1991; Wright and Stocker 1991; England 1993; Hughes and Weaver 1994). The midlatitude maximum in heat transport re-

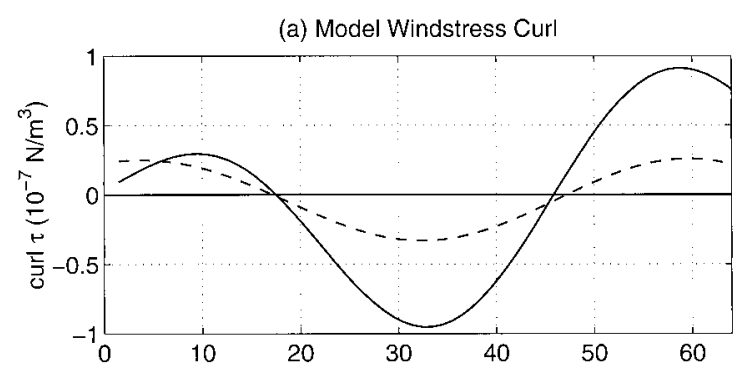

(b) Model Windstress

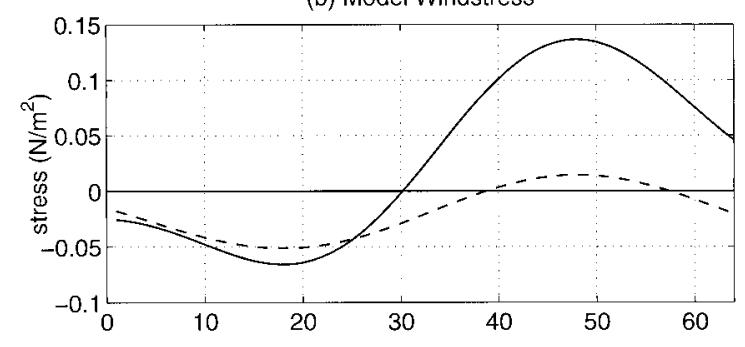

(c) Model Ekman Transport

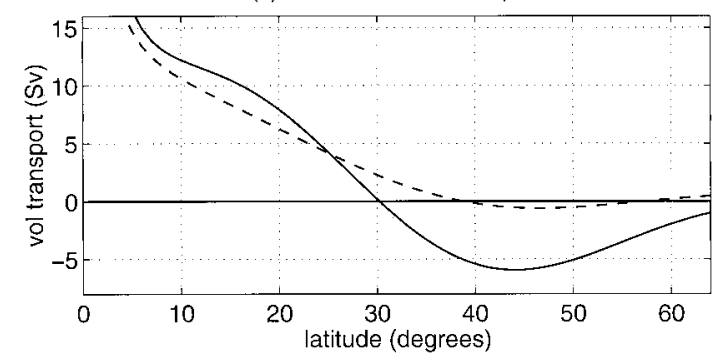

FIG. 2. (a) Wind stress curl, (b) wind stress, and (c) zonally integrated Ekman transport used in the numerical model. Solid curves represent realistic profiles used in most experiments, while dashed curves represent alternate profiles used in one experiment. Wind stress curl is calculated in spherical coordinates: $\operatorname{curl} \tau=-[1 / R \cos (\phi)][d(\tau$ $\cos (\phi))] / d \phi$.

flects the two factors-overturning transport and vertical temperature gradient- that control the heat transport in these runs. Overturning volume transport increases poleward, while vertical temperature gradient increases equatorward. These two roughly linear factors combine to form a parabola.

When a zonal wind is added, the heat transport increases at all latitudes (Fig. 3a). Because the equations of motion are nonlinear, it is not strictly valid to equate the heat transport to the sum of "purely wind driven" and "purely thermohaline" components. However, it is instructive to view $\Delta H$, the difference between heat transport in the wind and no-wind runs (Fig. 3b). The largest difference is equatorward of $30^{\circ} \mathrm{N}$, indicating that the subtropical cell (also equatorward of $30^{\circ} \mathrm{N}$ ) represents the wind's most important contribution to $H$. The coarse-resolution, strong-restoring run has virtually no wind-induced $H$ poleward of $30^{\circ} \mathrm{N}$. The high-resolution, strong restoring run has slightly higher (about $0.03 \mathrm{PW}$ ) heat transport than the coarse-resolution run at most latitudes and a significantly higher value (about $0.1 \mathrm{PW}$ ) close to the equator. The latter difference comes from 


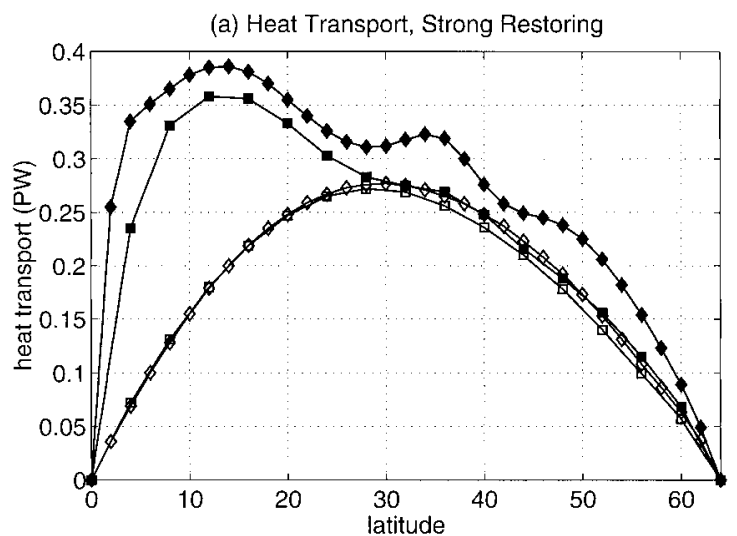

(b) Heat Transport Difference, Strong Restoring

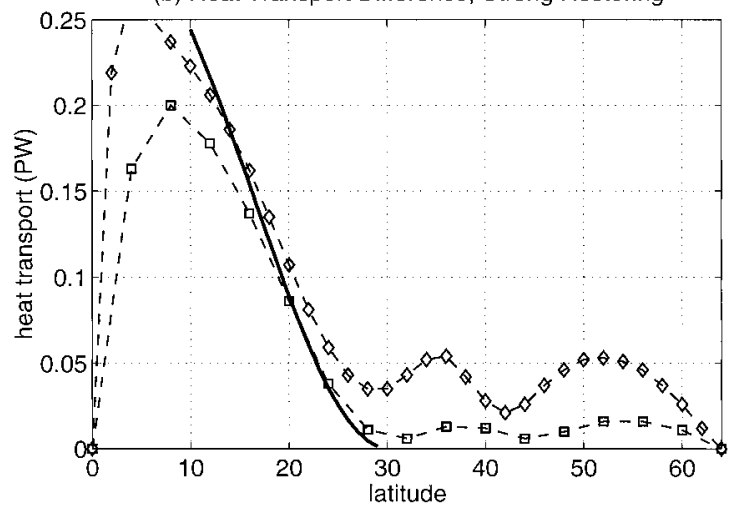

FIG. 3. Experiments with strong restoring. (a) Heat transport (in PW) for coarse resolution, with wind (solid squares) and without wind (open squares), and for high resolution, with wind (solid diamonds) and without wind (open diamonds). (b) Difference between wind and no-wind runs shown in (a), low resolution (squares) and high resolution (diamonds), along with prediction (thick solid curve) based on (11) and (13).

stronger shallow overturning near the equator, perhaps because in the high-resolution run the Ekman transport equation remains valid closer to the equator. In both strong-restoring runs, the zonally uniform surface temperature keeps the "gyre" (total advective heat transport minus overturning heat transport) component of heat transport relatively small.

On the whole, however, the heat transport between about $10^{\circ}$ and $30^{\circ} \mathrm{N}$ is not very sensitive to resolution. Using (11) and (13) to calculate the heat transport due to the subtropical cell (thick line, Fig. 3b), we see that the calculation gives an excellent estimate for the actual heat transport in both strong-restoring cases.

Weak temperature restoring decreases the temperature gradient in the meridional direction but increases it in the zonal direction so that overturning heat transport is weakened but gyre heat transport is strengthened. Thus, there is smaller heat transport in the no-wind case (Fig. 4a) and in the low-latitude wind contribution (Fig. 4b), while the midlatitude heat transport is strengthened (Fig. $4 \mathrm{~b})$. Our prediction for the subtropical contribution is
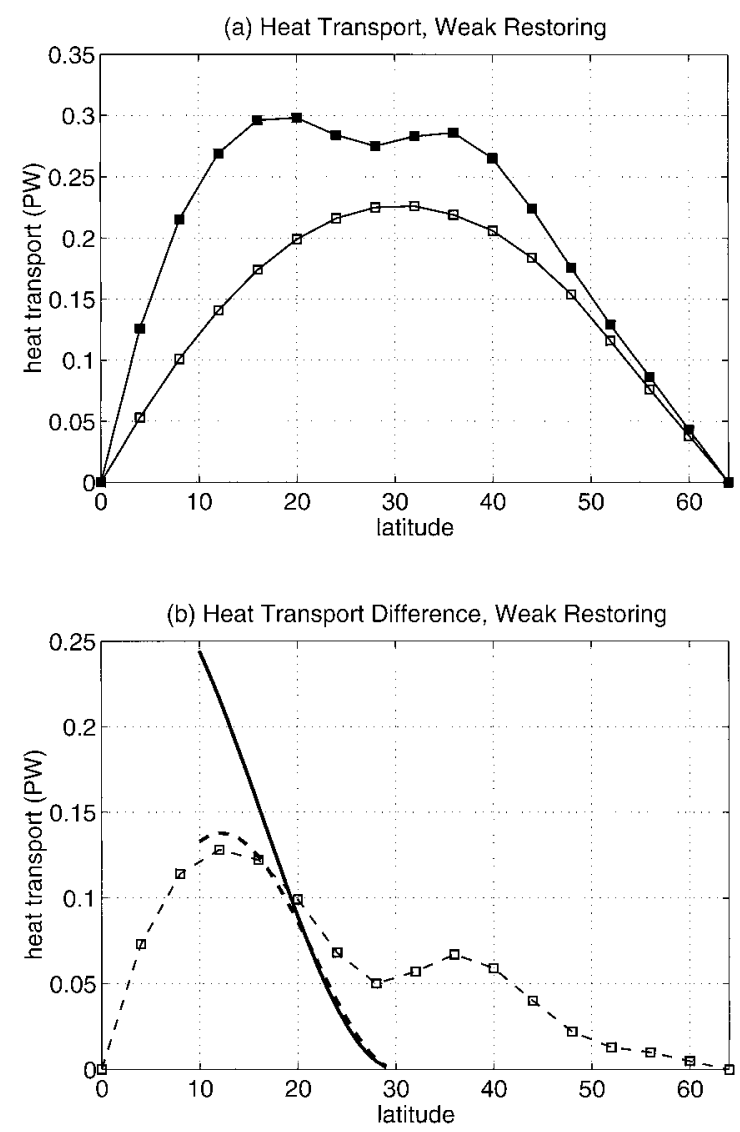

FIG. 4. Experiments with weak restoring and coarse resolution. (a) Heat transport (in PW), with wind (solid squares) and without wind (open squares). (b) Difference between wind and no-wind runs shown in (a) (squares); predictions based on reference surface temperature (thick solid curve) and on actual model zonal average surface temperature (thick dashed curve).

too large, but if we use the actual zonal average surface temperature instead of the restoring temperature, we obtain a good estimate (Fig. 4b).

The volume transport is also calculated by zonally integrating velocity within a given temperature interval rather than a given depth interval. The resulting streamfunction is then a function of latitude and temperature rather than latitude and depth (Fig. 5). At both coarse and high resolution, the subtropical cell strength calculated in the two ways is the same to within about $10 \%$. In temperature coordinates, adiabatic flow is represented by horizontal streamlines, so Fig. 5 shows that most, but not all, of the subsurface warming in the subtropical cell occurs within about $5^{\circ}$ latitude of the equator. However, we can think of some of this extraequatorial heating as being associated with the thermohaline circulation rather than the added effect of the subtropical winds. An indication of this is that, if we take the difference between the temperature-coordinate streamfunctions in the wind and no-wind runs, the streamlines associated with the subtropical cell are more horizontal outside the equatorial region (Fig. 5b). 
(a) Meridional Overturning, Wind

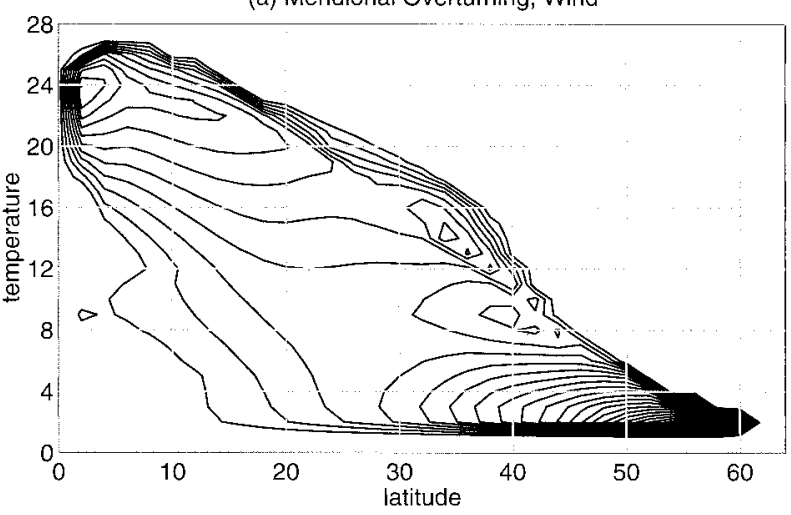

(b) Meridional Overturning, Wind - (No Wind)

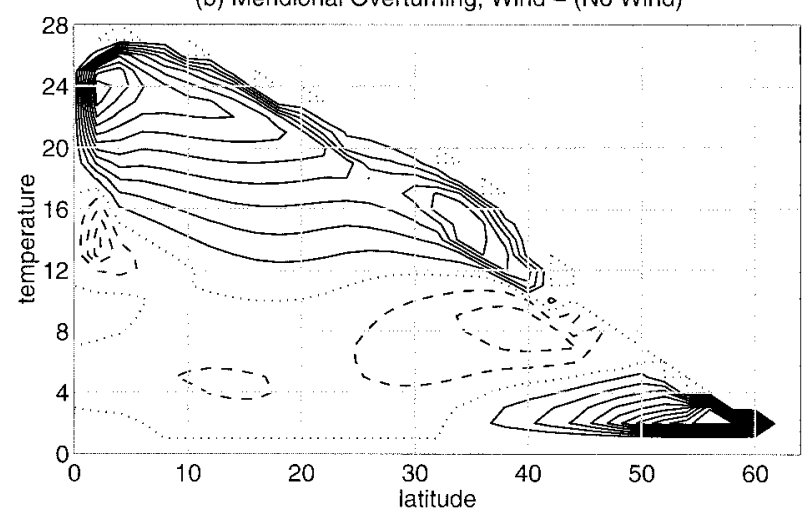

FIG. 5. Meridional overturning streamfunction for high-resolution runs in temperature-latitude coordinates. Contour interval is $1 \mathrm{~Sv}$; flow is clockwise around a high and anticlockwise around a low. (a) Experiment with wind. (b) Difference, wind-driven minus no-wind.

The theory presented in section 2 assumes that the wind does not induce any overturning at the latitude of zero wind stress. In the numerical experiments, this assumption is true for meridional flow zonally averaged at constant depth, but Fig. 5b shows that it is not true for flow averaged at constant temperature (see also Bryan 1991). The wind causes some extra warm (compared to the no-wind experiment) water to flow northward at the zero wind stress line, and is balanced by a colder southward flow. This overturning cell in temperature coordinates is associated with the fact that the nearsurface water flowing northward at $\phi_{0}$ in the western boundary current is warmer than any of the southward flow at the same latitude and depth. The transport involved in this warm cell ranges from $3.7 \mathrm{~Sv}\left(\mathrm{~Sv} \equiv 10^{6}\right.$ $\mathrm{m}^{3} \mathrm{~s}^{-1}$ ) for strong surface temperature restoring (coarse resolution) to $4.5 \mathrm{~Sv}$ for weak restoring, which has a warmer western boundary current. The difference between wind-driven and no-wind overturning (Fig. 5b) also shows a colder cell that transports heat southward, thus partially countering the warm cell associated with the western boundary current. The cause of this cell is not clear. In the high-resolution run, the warm cell adds
$0.08 \mathrm{PW}$ of northward heat transport at $30^{\circ} \mathrm{N}$, while the cold cell adds $-0.04 \mathrm{PW}$.

As an additional test on the theory, we employ an alternate wind stress in which the subtropical wind strength is about the same but the $\phi_{0}$ is moved up to $38.8^{\circ} \mathrm{N}$ (instead of $30^{\circ} \mathrm{N}$ ) and midlatitude westerlies are almost nonexistent (Fig. 2). This wind profile is still given by (13) but with $\gamma=\pi / 180, A=0.2$, and $B=$ 0.015 . The numerical experiment has coarse resolution and strong temperature restoring. In this case the heat transport in the numerical experiment is also correctly predicted by the theory, which shows increased heat transport between $20^{\circ}$ and $39^{\circ} \mathrm{N}$, and about the same heat transport between $10^{\circ}$ and $20^{\circ} \mathrm{N}$.

In further tests, we repeat the coarse-resolution, strong-restoring experiment in a two-hemisphere basin with horizontal diffusivity replaced by isopycnal diffusivity and the Gent-McWilliams eddy parameterization (Gent and McWilliams 1990; Gent et al. 1995). In one pair of experiments, the same equatorially symmetric boundary conditions are imposed, but the twobasin configuration eliminates the equatorial wall, and the vertical resolution is somewhat higher (6 levels in the top $350 \mathrm{~m}$ as opposed to 4). These changes make minimal differences in the solution, so the theoretical prediction continues to be a good approximation to the numerical results. In another pair of experiments, we introduce equatorial asymmetry by making a two-gridpoint-wide zonal channel in the Southern Hemisphere and imposing a surface property trend with the northern boundary $2.578^{\circ} \mathrm{C}$ warmer and 0.4125 psu saltier than the southern boundary. This forces about half of the deep northern sinking to flow into the Southern Hemisphere. The surface salinity profile also has a more realistic structure, with an equatorial minimum of about 34 psu and subtropical maxima of about 36.5 psu at latitude $25^{\circ}$. In this pair of experiments, maximum windinduced heat transport (average of Northern and Southern Hemispheres) is $0.22 \mathrm{PW}$, close to the predicted value and to the simpler experiments. The heat transport in the region of interest was somewhat greater in the Northern Hemisphere than in the Southern, but each hemisphere was within $14 \%$ of the average of the two hemispheres.

\section{Estimates from observed properties}

We now use (11) to estimate heat transport for the five subtropical gyres (North and South Atlantic, North and South Pacific, and south Indian) of the real ocean. Climatological sea surface temperature comes from the World Ocean Atlas '94 (Levitus and Boyer 1994) and climatological zonal wind stress comes from COADS (da Silva et al. 1994). Both datasets are gridded on $1^{\circ}$ squares and averaged (sea surface temperature) or integrated (wind stress) zonally across the domain. The boundaries of the integration domain are taken to be continents, as well as New Guinea and Borneo for the 


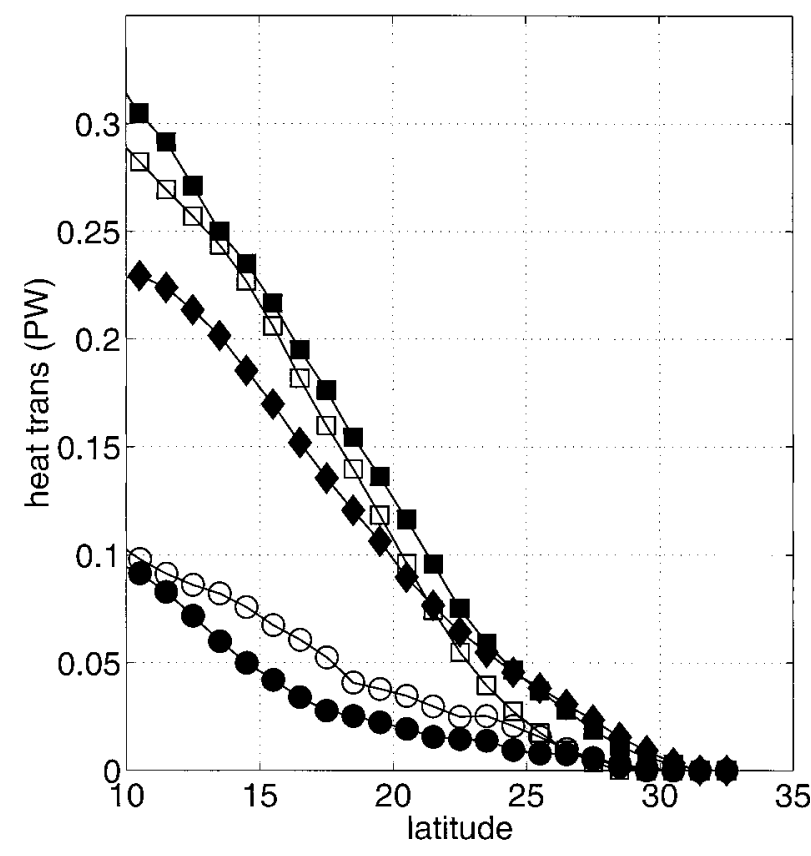

FIG. 6. Meridional heat transport estimates (PW) as a function of latitude for the subtropical cells in the Atlantic (circle), Pacific (square), and Indian (diamond) Oceans, for Northern (open markers) and Southern (closed markers) Hemispheres.

western edge of the Pacific and New Guinea, Java, and Sumatra for the eastern edge of the Indian Ocean. The Atlantic basin includes the Caribbean and Gulf of Mexico. As in section 3, integration of (11) starts at $\phi_{0}$, the latitude of zero zonal-average wind stress; this latitude is close to $30^{\circ}$ for all basins.

The different basins have widely differing estimates of subtropical cell heat transport (Fig. 6), though the general shape of the curves are all similar to the idealized profile (see Fig. 3). As Table 2 shows, the Pacific has a much larger estimated heat transport than the Atlantic because it has a much larger Ekman volume transport, a consequence of the Pacific's great zonal width. The Pacific and especially the Indian also have larger surface temperature ranges than the Atlantic.

Given our current state of knowledge of the ocean, it is difficult to test these estimates. Since we cannot remove wind forcing from the real ocean in order to isolate changes caused by the wind, a direct test is not possible. By combining the prediction here with estimates of the thermohaline component and wind-driven gyre component of the heat transport, we could test the the combined estimate based on all three components. Such a detailed test is beyond the scope of this study. However, comparison with observations of total heat transport raises some interesting points.

Total poleward heat transport in the real ocean is estimated to be around $1 \mathrm{PW}$ at $24^{\circ} \mathrm{N}$ in the Atlantic (Hall and Bryden 1982; Roemmich and Wunsch 1985; Macdonald and Wunsch 1996), 0.8 PW (Bryden et al. 1991) or 0.5 PW (Macdonald and Wunsch 1996) at the same
TABLE 2. Transport estimates from observed surface boundary conditions: $\Phi_{\mathrm{E}}$ is zonally integrated Ekman transport at latitude $10^{\circ}(\mathrm{Sv})$, $\Delta \theta_{S}$ is difference between zonally averaged sea surface temperature at latitude $10^{\circ}$ and latitude of zero wind stress (C), and $H_{\max }$ is estimated heat transport at latitude $10^{\circ}(\mathrm{PW})$

\begin{tabular}{lrll}
\hline \hline \multicolumn{1}{c}{ Ocean } & $\Phi_{\mathrm{E}}$ & $\Delta \theta_{S}$ & $H_{\max }$ \\
\hline North Atlantic & 11 & 5.1 & 0.10 \\
South Atlantic & 9 & 5.5 & 0.10 \\
North Pacific & 32 & 7.8 & 0.29 \\
South Pacific & 26 & 7.7 & 0.31 \\
South Indian & 13 & 8.4 & 0.23 \\
\hline
\end{tabular}

latitude in the Pacific, and a maximum of $0.8 \mathrm{PW}$ in the south Indian at $15^{\circ} \mathrm{S}$ (Lee and Marotzke 1998). Our estimate of the subtropical cell contribution is thus a small component in the North Atlantic but a significant one in the North Pacific, which is consistent with the belief that the Atlantic, but not the Pacific, is dominated by a deep thermohaline cell. However, our estimate of $0.2 \mathrm{PW}$ in the south Indian Ocean is surprisingly small given the results of Lee and Marotzke (1997, 1998), which imply that heat transport there is dominated by the wind-driven, shallow cell (irrespective of the presence or absence of a seasonal cycle). The discrepancy may be due to over $0.4 \mathrm{PW}$ of northward heat transport that occurs at both $30^{\circ} \mathrm{S}$ and the equator (Lee and Marotzke 1998). The cross-equatorial heat and volume fluxes are related to the unique geometry of the Indian Ocean and are outside the scope of our theory. The heat transport at $\phi_{0}$ may also be related to this geometry.

We also compare our volume transports to observations. Some recent measurements of the shallow, subsurface, equatorward flow in the Pacific show about 28 $\mathrm{Sv}$ feeding the Equatorial Undercurrent from the south and another $18 \mathrm{~Sv}$ feeding it from the north (Wijffles 1993; Butt and Lindstrom 1994; Johnson and McPhaden 1998) with an additional 5 to $15 \mathrm{~Sv}$ of Northern Hemisphere flow diverted into the Indonesian Throughflow (Gordon 1986). These values are in broad agreement with the Ekman volume transport figures in Table 2, which is consistent with the idea of a shallow cell driven by Ekman transport.

\section{Conclusions}

We derive a theoretical expression for the subtropical and tropical wind-driven meridional heat transport. The theory assumes that the dominant contribution to this component of heat transport is the subtropical cell consisting of poleward Ekman transport and a deeper geostrophic return flow. The total volume transport of the cell is given by the maximum Ekman transport; the temperature of the return volume transport is calculated assuming that it follows isotherms after being subducted. A further assumption of the theory is that at the latitude of zero wind stress, the wind does not drive meridional overturning as measured in temperature coordinates. The theory was tested by several numerical 
experiments with realistic physics but idealized configurations. At the zero wind stress latitude, the numerical experiments have a temperature-coordinate overturning of a few Sverdrups associated with the western boundary current (producing poleward heat transport), as well as a colder circulation carrying heat equatorward. Despite these violations of our initial assumption, the theory gives a good prediction of the net heat transport associated with the wind, in part because the components not included in the theory tend to cancel each other.

While we have demonstrated the simplicity of estimating heat transport for this one mechanism, some care must be taken in applying it to the real ocean. By ignoring meridional wind stress, we exclude coastal upwelling and downwelling zones that may account for significant cross-isotherm flow and may change the strength and temperature range of the subtropical cell. Our theory also has isotherms coincident with isopycnals; in the real ocean temperature mixing along isopycnals may also modify our picture. Mesoscale eddies make a small $(0.05 \mathrm{PW})$ contribution in a coupled ocean-atmosphere model (Fanning and Weaver 1997). Seasonal variations in both surface temperature and wind forcing also complicate the ventilation paths assumed here. Seasonal variations in heat transport are large, especially at low latitudes (Levitus 1987; Adamec et al. 1993; Molinari et al. 1990; Lee and Marotzke 1998).

Our expression for the meridional volume transport in the subtropical cell is much simpler than expressions for subduction strength (Marshall et al. 1993). Most of the non-Ekman contribution to subduction occurs because of horizontal geostrophic flow out of the mixed layer. This effect only occurs in the presence of meridional gradients in mixed layer depth, which are absent in our model in the region of interest, equatorward of $\phi_{0}$. We suspect that this absence is related to the lack of seasons in our model. "Subduction" refers to water that permanently leaves the mixed layer. For this reason it is appropriate to base subduction calculations on the relatively deep mixed layer at the end of winter, when there is a large gradient in depth between $25^{\circ}$ and $30^{\circ} \mathrm{N}$ in both the Atlantic and Pacific Oceans (Levitus 1982). For heat transport, however, it is most appropriate to simply integrate (1) in time. Rectification of seasonal variations appears significant for the North Atlantic ( $\mathrm{Yu}$ and Malanotte-Rizzoli 1998), but Indian Ocean results (Lee and Marotzke 1998) indicate that the dynamics of seasonal heat transport variability are linear in winddominated situations. More work is needed before we know whether the apparent Atlantic rectification is due to the strong thermohaline circulation there.

Using observed wind, SST, and basin width parameters for the Atlantic Ocean, we obtain a subtropical cell heat transport of about $0.1 \mathrm{PW}$ at $10^{\circ} \mathrm{N}$ and $10^{\circ} \mathrm{S}$. The south Indian Ocean, with a greater meridional temperature contrast, has a value of about $0.23 \mathrm{PW}$, while the wider Pacific Ocean has about $0.3 \mathrm{PW}$ in each hemisphere. The Indian prediction appears to be a severe underestimate of the actual wind-driven component, possibly due to cross-equatorial flow related to the presence of a northern boundary in the subtropical north Indian Ocean.

While the relative importance of the subtropical cell varies from ocean to ocean, there is reason to be interested in this component of heat transport in all the basins. From a theoretical point of view, the direct link between the wind forcing and the heat transport is relevant to the possibility of decadal oscillations arising from feedback between the wind and oceans (see Gu and Philander 1997; Kleeman et al. 1999). From an observational point of view, the strong link between surface conditions (wind stress and ocean temperature) and the heat transport suggests a convenient way to monitor at least one component of the heat transport, though care must be taken in applying the steady subtropical cell dynamics to the time-dependent case (Klinger et al. 1999).

Most importantly, perhaps, we feel that we have been able to fill an entry in the array of timescales and processes that governs meridional overturning and hence the bulk of the heat transport in the ocean. Significant progress has recently been made in developing a theory for steady-state thermohaline meridional overturning (Marotzke 1997; Marotzke and Klinger 2000) and there has been established a robust dynamical picture of seasonal and faster variations in wind-driven overturning (Böning and Herrmann 1994; Lee and Marotzke 1998). Here, we have addressed the steady-state wind-driven overturning, albeit not its mass transport but directly its associated heat transport.

Acknowledgments. J.M. was supported in part by NSF Grant OCE-9617570, and B.A.K. was supported by NSF Grant OCE-9521138. Kevin Kohler provided computer assistance. Jay McCreary made many useful suggestions concerning the manuscript. We thank the reviewers for their comments and Peng Lu for some helpful discussion.

\section{REFERENCES}

Adamec, D., M. M. Rienecker, and J. M. Vukovich, 1993: The timevarying characteristics of the meridional Ekman heat transport for the World Ocean. J. Phys. Oceanogr., 23, 2704-2716.

Böning, C. W., and P. Herrmann, 1994: Annual cycle of poleward heat transport in the ocean: Results from high-resolution modelling of the North and equatorial Atlantic. J. Phys. Oceanogr., 24, 91-107.

Bryan, F., 1987: Parameter sensitivity of primitive equation ocean general circulation models. J. Phys. Oceanogr., 17, 970-985.

Bryan, K., 1991: Poleward heat transport in the ocean, Tellus, 43A, 104-115.

Bryden, H. L., D. H. Roemich, and J. A. Church, 1991: Ocean heat transport across $24 \mathrm{~N}$ in the Pacific. Deep-Sea Res., 38, 229324.

Butt, J., and E. Lindstrom, 1994: Currents of the east coast of New 
Ireland, Papua New Guinea, and their relevance to the regional undercurrents in the western equatorial Pacific Ocean. J. Geophys. Res., 99, 12 503-12 514

Bye, J. A. T., and G. Veronis, 1980: Poleward heat flux by an ocean gyre. Dyn. Atmos. Oceans, 4, 101-114.

Cox, M. D., and K. Bryan, 1984: A numerical model of the ventilated thermocline. J. Phys. Oceanogr., 14, 674-687.

da Silva, A., C. Young, and S. Levitus, 1994: Atlas of Surface Marine Data, 1994, Vol. 1: Algorithms and Procedures, NOAA Atlas NESDIS 6, U.S. Department of Commerce, Washington, DC, 83 pp.

Davis, R. E., 1976: Predictability of sea surface temperature and sea level pressure anomalies over the North Pacific Ocean. J. Phys. Oceanogr., 6, 249-266.

England, M., 1993: Representing the global-scale watermasses in ocean general circulation models. J. Phys. Oceanogr., 23, $1523-$ 1552 .

Fanning, A. F., and A. J. Weaver, 1997: A horizontal resolution and parameter sensitivity study of heat transport in an idealized coupled climate model. J. Climate, 10, 2469-2478.

Fu, L. L., 1981: The general circulation and meridional heat transport of the subtropical South Atlantic determined by inverse methods. J. Phys. Oceanogr., 11, 1171-1193.

Gent, P. R., and J. C. McWilliams, 1990: Isopycnal mixing in ocean circulation models. J. Phys. Oceanogr., 20, 150-155.

—, J. Willebrand, T. J. McDougall, and J. C. McWilliams, 1995: Parameterizing eddy-induced tracer transports in ocean circulation models. J. Phys. Oceanogr., 25, 463-474.

Gordon, A. L., 1986: Interocean exchange of thermocline water. $J$. Geophys. Res., 91, 5037-5046.

Gu, D., and S. G. H. Philander, 1997: Interdecadal climate fluctuations that depend on exchanges between the tropics and extratropics. Science, 275, 805-807.

Hall, M. M., and H. L. Bryden, 1982: Direct estimates and mechanisms of ocean heat transport. Deep-Sea Res., 29, 339-359.

Huang, R. X., and S. Russell, 1994: Ventilation of the subtropical North Pacific. J. Phys. Oceanogr., 24, 2589-2605.

Hughes, T. M. C., and A. Weaver, 1994: Multiple equilibria of an asymmetric two-basin ocean model. J. Phys. Oceanogr., 24, 619-637.

Johnson, G. C., and M. J. McPhaden, 1999: Interior pycnocline flow from the subtropical to the equatorial Pacific Ocean. J. Phys. Oceanogr., 29, 3073-3098.

Kleeman, R., J. P. McCreary, and B. A. Klinger, 1999: A mechanism for generating ENSO decadal variability. Geophys. Res. Lett., 26, 1743-1746.

Klinger, B. A., 1996: A kinematic model of wind-driven meridional heat transport. J. Phys. Oceanogr., 26, 131-135.

- , and J. Marotzke, 1999: Behavior of double hemisphere thermohaline flows in a single basin. J. Phys. Oceanogr., 29, 382399.

_ J. P. McCreary, and R. Kleeman, 1999: Equatorial Pacific SST response to extra-tropical decadal windstress forcing. Eos, Trans. Amer. Geophys. Union, 80 (Suppl.), 217.

Kraus, E. B., and S. Levitus, 1986: Annual heat flux variations across the tropic circles. J. Phys. Oceanogr., 16, 1479-1486.

Lee, T., and J. Marotzke, 1997: Inferring meridional mass and heat transports of the Indian Ocean by fitting a general circulation model to climatological data. J. Geophys. Res., 102, 10585 10602 .

— and — 1998: Seasonal cycles of meridional overturning and heat transport of the Indian Ocean. J. Phys. Oceanogr., 28, $923-$ 943.

Levitus, S., 1982: Climatological Atlas of the World Ocean. NOAA
Prof. Paper No. 13, U.S. Govt. Printing Office, Washington, DC, $173 \mathrm{pp}$.

_ 1987: Meridional Ekman heat fluxes for the World Ocean and individual ocean basins. J. Phys. Oceanogr., 17, 1484-1492. , and T. P. Boyer, 1994: World Ocean Atlas 1994. Vol. 4: Temperature, NOAA Atlas NESDIS 4, $117 \mathrm{pp}$.

Lu, P., J. P. McCreary, and B. A. Klinger, 1998: Meridional circulation cells and the source waters of the Pacific Equatorial Undercurrent. J. Phys. Oceanogr., 28, 62-84.

Luyten, J., J. Pedlosky, and H. Stommel, 1983: The ventilated thermocline. J. Phys. Oceanogr., 13, 292-309.

Macdonald, A., and C. Wunsch, 1996: An estimate of global ocean circulation and heat fluxes. Nature, 382, 436-439.

Marotzke, J., 1997: Dynamics of equatorially asymmetric thermohaline circulations. J. Phys. Oceanogr., 27, 1713-1728.

— , and J. Willebrand, 1991: Multiple equilibria of the global thermohaline circulation. J. Phys. Oceanogr., 21, 1372-1385.

- and D. W. Pierce, 1997: On spatial scales and lifetimes of SST anomalies beneath a diffusive atmosphere. J. Phys. Oceanogr., 27, 133-139.

- , and B. A. Klinger, 2000: The dynamics of equatorially asymmetric thermohaline circulation. J. Phys. Oceanogr., in press.

Marshall, J., A. J. G. Nurser, and R. G. Williams, 1993: Inferring the subduction rate and period over the North Atlantic. J. Phys. Oceanogr., 23, 1315-1329.

McCreary, J., and P. Lu, 1994: Interaction between the subtropical and equatorial ocean circulations: The subtropical cell. J. Phys. Oceanogr., 24, 466-497.

Molinari, R. L., E. Johns, and J. F. Festa, 1990: The annual cycle of meridional heat flux in the Atlantic Ocean at $26.5^{\circ} \mathrm{N}$. J. Phys. Oceanogr., 20, 476-482.

Nurser, A. J. G., and J. C. Marshall, 1991: On the relationship between subduction rates and diabatic forcing of the mixed layer. J. Phys. Oceanogr., 21, 1793-1802.

Pacanowski, R. C., 1996: MOM 2 Documentation, User's Guide and Reference Manual, GFDL Ocean Tech. Rep. 3.2, Geophysical Fluid Dynamics Laboratory/NOAA, Princeton, NJ, 329 pp. [Available from GFDL/NOAA, Princeton University, P.O. Box 308, Princeton, NJ 08542.]

Pedlosky, J., 1987: An inertial theory of the equatorial undercurrent. J. Phys. Oceanogr., 17, 1978-1985.

Peixoto, J. P., and A. H. Oort, 1992: Physics of Climate. Amer. Inst. Phys., $520 \mathrm{pp}$.

Philander, S. G. H., 1978: Forced oceanic waves. Rev. Geophys. Space Phys., 16, 15-46.

Rahmstorf, S., and J. Willebrand, 1995: The role of temperature feedback in stabilizing the thermocline circulation. J. Phys. Oceanogr., 25, 787-805.

Wang, X., P. H. Stone, and J. Marotzke, 1995: Poleward heat transport in a barotropic ocean model. J. Phys. Oceanogr., 25, 256-265.

Wijffels, S. E., 1993: Exchanges between hemispheres and gyres: A direct approach to the mean circulation of the equatorial Pacific. Ph.D. thesis, WHOI Publ. 93-41, MIT/WHOI Joint Program, 267 pp.

Willebrand, J., S. G. H. Philander, and R. C. Pacanowski, 1980: The oceanic response to large-scale atmospheric disturbances. $J$. Phys. Oceanogr., 10, 411-429.

Wright, D. G., and T. F. Stocker, 1991: A zonally averaged ocean model for the thermohaline circulation. Part II: Interocean circulation in the Pacific-Atlantic basin system. J. Phys. Oceanogr., 21, 1725-1739.

Yu, L., and P. Malanotte-Rizzoli, 1998: Inverse modeling of seasonal variations in the North Atlantic Ocean. J. Phys. Oceanogr., 28, 902-922. 